Research Article

\title{
Construction of Risk Evaluation Index System for Power Grid Engineering Cost by Applying WBS-RBS and Membership Degree Methods
}

\author{
Jiao Wang (iD \\ School of Business Economic Management, Northeast Electric Power University, Jilin 132012, China \\ Correspondence should be addressed to Jiao Wang; dbd12037134@126.com
}

Received 3 March 2020; Accepted 29 June 2020; Published 4 August 2020

Guest Editor: Weilin Xiao

Copyright (C) 2020 Jiao Wang. This is an open access article distributed under the Creative Commons Attribution License, which permits unrestricted use, distribution, and reproduction in any medium, provided the original work is properly cited.

\begin{abstract}
Based on the perspective of cost risk management of the entire process of power grid construction project, the WBS-RBS risk identification method is applied. The risk factors of power grid engineering cost are comprehensively identified from the five major engineering cost formation stages: investment decision estimate stage, design estimate stage, bidding price stage, construction budget stage, and final account stage. Combined with the basic data obtained from the questionnaire, the membership degree method is adopted to screen the key indicators of the preliminary factors of cost risk and then eliminate the redundant indicators. Furthermore, a set of simple and efficient risk evaluation index system for power grid engineering cost is constructed in order to improve the risk evaluation and management level of power grid construction project in China.
\end{abstract}

\section{Introduction}

An important content of power grid construction project management is cost risk evaluation. Scientific project risk evaluation can ensure that the cost of the entire process of power grid engineering can be controlled effectively. Through the rational use of funds, the goal of optimal return on project investment can be achieved.

The research on the risk evaluation of power grid engineering cost mainly began at the beginning of this century so that the related literature is still relatively limited. Among these literature studies, the study in [1] adopts data envelopment analysis (DEA) to investigate the cost risk existed in the process of power grid construction. The study in [2] adopts Monte Carlo method to simulate and predict the risks encountered in power grid engineering projects. The study in [3], in order to solve the problem of uncertainty in the power grid engineering cost caused by the adoption of single prediction model, adopts artificial neural network (ANN) and genetic algorithm (GA). It has optimized the prediction model of power grid engineering cost and improved the accuracy. However, none of the above literature has established a relatively complete cost risk evaluation index system for power grid engineering, which is not conducive to the project cost prevention and control personnel to evaluate and deal with risks in a timely and effective manner. The study in [4] analyzes risk sources of power grid engineering through the application of the fault tree analysis (FTA). Although engineering cost risk evaluation index system is constructed, the subjective factors are too heavy, and it lacks objective credibility when used for evaluation. The study in [5] analyzes the risks that may be involved in the power grid engineering cost qualitatively and quantitatively and adopts fuzzy evaluation method to calculate risk degree of engineering projects. Nevertheless, it fails to identify key risk indicators so that the practical application efficiency of the risk evaluation index system is reduced. The study in [6] systematically classifies power grid cost risk factors, draws the fishbone diagram, and analyzes the sensitivity of individual cost factors. Although it identifies the risk factors that affect cost, it does not evaluate the extent to which they may cause cost losses.

However, in other large-scale engineering construction fields, some scholars had adopted WBS-RBS method to 
evaluate the project cost risk and obtained relatively ideal results. The study in [7] had utilized WBS-RBS method combined with literature reading to identify the risk factors of civil engineering projects and constructed a risk evaluation index system of engineering cost including $28 \mathrm{sec}-$ ondary risk factors, which can provide a basis for risk managers to make risk decisions. The study in [8] had adopted work breakdown structure-risk breakdown structure (i.e., WBS-RBS) method to identify the risk of water conservancy project in the whole process management according to the complicated characteristics of water conservancy project, so as to effectively control the cost risk of the whole process of water conservancy projects. The study in [9] had applied WBS-RBS method to identify and analyze the risks of subway construction, which improved the risk management and control level of subway construction cost. However, the WBS-RBS risk assessment method used in the above mainly focuses on the evaluation of the importance of risk but neglects the importance of the project itself, which also affects the risk. The study in [10] proposed a risk assessment method based on WBS-RBS-DSM, which is on the basis of the traditional WBS-RBS matrix, to calculate the comprehensive risk value faced by the project. But the application conditions of DSM model are relatively strict, which is difficult to meet in practical application. The study in [11], in the process of risk identification, had applied WBS-RBS risk identification method to decompose and analyze the project systematically. He used Delphi method to identify each preliminary risk factor of the identification matrix systematically and screened out the key factors affecting the project cost. However, due to the existence of many subjective factors in the discrimination process, the evaluation results are not objective.

In conclusion, on the basis of previous research on cost risk assessment of nongrid projects by WBS-RBS method, this paper improves WBS-RBS method through the analysis of membership degree. WBS-RBS method based on the analysis of membership degree is also applied to the risk evaluation of power grid engineering cost, which reflects the time, stage, and management object of project risk in detail, so as to enable the relevant organizations of the project to defend against the risk in advance. In addition, compared with the traditional risk identification method, the WBSRBS membership analysis method could identify risks in each stage of the power grid engineering life cycle in detail, which makes up for the omission of traditional risk identification methods such as brainstorming, Delphi, or expert investigation in practical application due to the randomness and subjectivity.

Therefore, based on the research results on current risk evaluation of power grid engineering cost, this paper starts with the entire process of power grid construction and adopts WBS-RBS method to identify cost risk factors for the entire process of power grid construction project in China. Then, membership degree method is applied to select key factors that affect power grid engineering cost from the preliminary identification indicators of power grid construction project risks, so as to establish a relatively scientific, streamlined, and appropriate system for risk evaluation of power grid engineering cost. This enables China's power grid engineering cost analysts and project risk-related managers to fully and clearly recognize the risk factors of cost in each stage of the entire project process, thereby achieving the goal of effective control of power grid engineering cost in advance.

\section{Influence of Each Stage of Power Grid Construction on Cost}

Risk evaluation of power grid engineering cost is integral to power grid construction project management. Because the project cost management runs through the entire process of power grid project construction, the risk evaluation of power grid engineering cost is staged and complex. The extent to which each stage of the current power grid engineering affects the cost is illustrated in Figure 1.

According to Figure 1, the impact of the investment decision-making stage on project cost is $75 \%-95 \%$, the design stage is $35 \%-75 \%$, the bidding stage is $20 \%-30 \%$, the construction stage is $35 \%-50 \%$, and the final account stage is $0-5 \%$. It is clear from Figure 1 that the investment decisionmaking stage and the design stage before the implementation of the project are the key points of cost control. Consequently, relevant work such as identifying risk factors that affect engineering cost, screening evaluation indicators, and constructing index system should be carried out in the investment decision-making stage, which is the early stage of power grid engineering.

\section{Features of Power Grid Engineering Cost Risk Management and Design Principles of the Index System}

3.1. Features of Power Grid Engineering Cost Risk Management. The risk of power grid engineering cost widely exists in the entire process of power grid construction mainly due to the following three aspects: Firstly, the value of construction products is the basis for the formation of engineering cost. Secondly, the power grid construction itself is unique and complex. Thirdly, there are many differences between the composition and calculation of power grid engineering cost and other large- and medium-sized construction projects. The study in [12] analyzes the factors that affect power grid engineering cost from both macroperspectives and microperspectives. From the macroperspective, government behavior, market supply and demand, construction science and technology, and socioeconomic development may all have a direct or indirect impact on the power grid engineering cost. From the microperspective, for a specific power grid construction project, its design level, construction level, natural environment conditions, owners' value orientation, and management behavior could directly or indirectly affect its engineering cost and run through the entire process of power grid construction.

In addition, due to the influence of natural conditions such as geology and geomorphology, as well as the unbalanced economic development level of various provinces in 


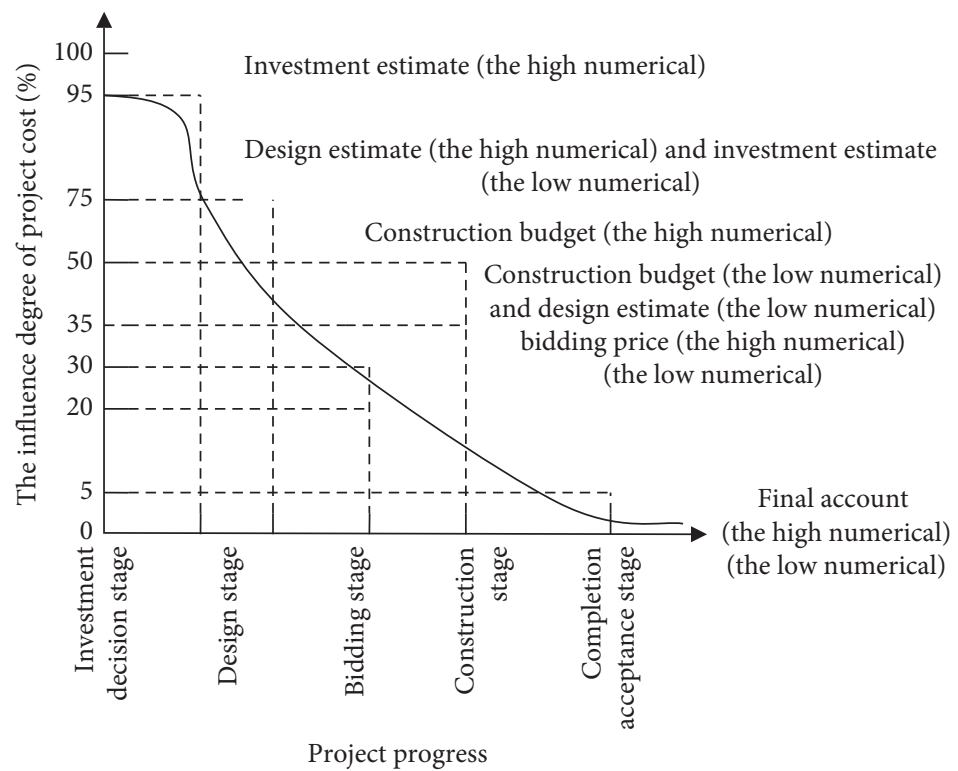

Figure 1: Project cost process.

China, the risk of power grid engineering cost varies in different regions. In view of similar natural and geological conditions and economic levels in Northeast China, it is more appropriate to analyze the risk factors of power grid engineering cost. Therefore, this paper focuses on the risk factors that affect the power grid engineering cost in Northeast China. The study in [13] considers that no matter it is the cost management of power transmission and transformation project or the cost management of other types of engineering projects, it is necessary to identify and analyze the cost risk. This work should be carried out in the early stage of risk management and run through the entire process of engineering cost. Identifying and analyzing the risk factors of power grid engineering cost is the premise and basis of cost risk estimation, cost risk evaluation, and cost risk response. The WBS-RBS risk identification method has a good effect on the risk identification process of other largeand medium-sized construction projects. This method is comprehensive and clear in analyzing the risk factors, and the conclusions obtained are more accurate. Based on the above factors, this paper introduces the WBS-RBS method for the first time to systematically decompose and initially identify the risk factors of power grid engineering cost risks and then combines expert questionnaire survey opinions and adopts the membership degree method to further screen the preliminary risk indicators, so as to acquire the key risk factors that need to be focused on prevention and control in power grid engineering cost.

\subsection{Design Principles of the Cost Risk Evaluation Index System.} Risk evaluation index system for power grid engineering cost is a collection of potential risk factors at all stages in the entire process of power grid construction. This paper starts from the perspective of risk management in the entire process of power grid engineering cost, combines the actual conditions of power grid engineering, and identifies and screens out key risk factors that affect power grid engineering cost in China based on the design principles of evaluation indicators to establish a clear and simple cost risk evaluation index system. The specific design principles are as follows.

(1) Principle of scientificity: in the selection of indicators, the calculation of the selected indicators is required to be clear and accurate. The content reflected should be objective, comprehensive, and standardized. Those fuzzy factors cannot be selected as evaluation indicators.

(2) Principle of hierarchy: the cost risk evaluation indicators cover a wide range and the evaluation system constructed is relatively complex. Therefore, the identification and selection of indicators should not only meet the integrity of the evaluation system, but also reflect the hierarchical relationship between cost risk factors.

(3) Principle of feasibility: when constructing cost risk evaluation index system, it is necessary to fully consider whether the information expressed by the indicators is accurate and available or not, which determine whether the evaluation index system can be effective or not in practical applications.

(4) Principle of combining qualitative and quantitative analysis: in order to avoid too many subjective factors or improper processing of objective data involved in evaluation process that lead to inaccurate evaluation results, qualitative and quantitative analysis methods should be combined to design a balanced and scientific evaluation index system.

(5) Principle of relative independence: in order to acquire objective and accurate evaluation results, it is required to maintain great relative independence between the indicators in the evaluation system and 
to avoid the high overlap of the risk information attribute reflected between the indicators to cause problems with indicator membership attribute.

\section{WBS-RBS Model Introduction}

WBS (work breakdown structure) refers to forming a WBS tree, which is a relatively complete work breakdown structure in project management, by decomposing the tasks of an engineering project layer by layer into a minimum work package (WP). RBS (risk breakdown structure) is derived from the construction principle of the work breakdown structure (WBS), and the RBS tree is a more comprehensive risk breakdown structure in project risk management. Since the breakdown structures of WBS and RBS are both guided by project goals, the two can be combined to form a WBS-RBS matrix to determine the risks existing at different stages of the project and analyze the extent of the loss caused by the risk factors to the project and probability of occurrence [11]. The WBS-RBS model is illustrated in Figure 2.

The WBS tree is shown in the upper part of Figure 2. The American Project Management Institute (PMI) defines WBS as a hierarchical decomposition of the work that the project team needs to perform to create the required deliverables and achieve the goal of completing the project. The planned work included in the lowest level of its structure is called work package (WP) [10]. The RBS tree is shown in the left half of Figure 2. RBS refers to the risk breakdown structure formed by degrading the risks faced by the project to the most basic risk events through hierarchical decomposition technology.

The lowest level work package (WP) of the work breakdown structure tree is regarded as the column of the WBS-RBS matrix, and the lowest level basic risk event of the risk breakdown structure tree is regarded as the row of the WBS-RBS matrix to construct a complete WBS-RBS risk identification matrix. Then, whether the work package (WP) faces corresponding risks can be judged one by one according to the matrix elements [14].

\section{Identification of Influencing Factors of Power Grid Engineering Cost Risk Based on the WBS-RBS Method}

The risk evaluation of power grid engineering cost should run through the entire process of the implementation of power grid construction project and is continuous and systematic. It mainly includes five stages: investment decision estimate, design estimate, bidding price, construction budget, and final account. This paper adopts WBS-RBS method to decompose the entire process of power grid engineering cost and analyze the potential risk factors at the corresponding stage.

5.1. WBS Tree in the Entire Process of Power Grid Engineering Cost. The entire process of power grid engineering cost management mainly includes the following five stages:

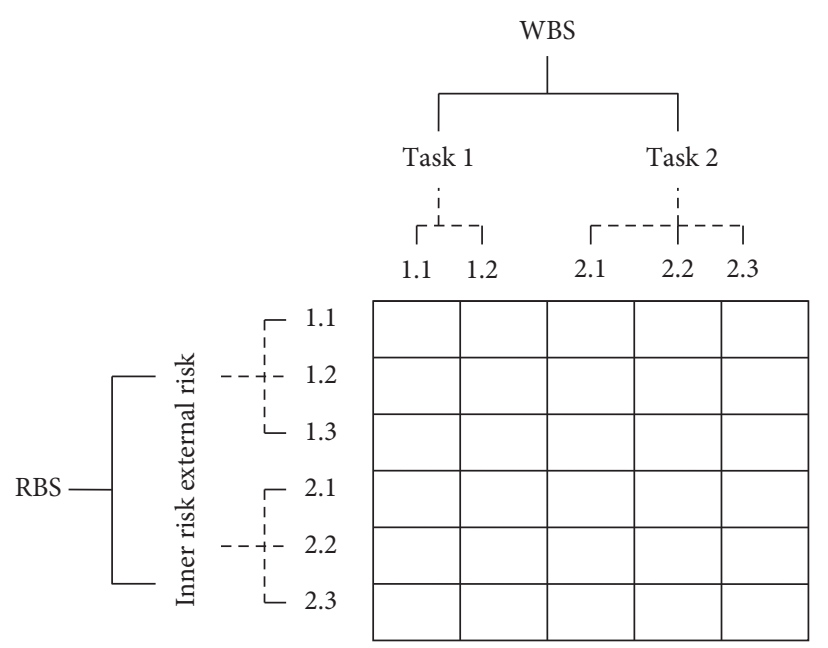

FIGURE 2: WBS-RBS matrix diagram.

estimation management in investment decision-making stage, budget estimation management in design stage, price management in bidding stage, budget management in construction stage, and final account management (including settlement) in completion stage, which form a complete cost management system for the entire process of power grid engineering. The cost management work of each stage continues to be broken down to the specific activity work package (WP), and finally the WBS tree can be constructed as illustrated in Figure 3.

5.2. RBS Tree of Cost Risk in Each Stage of Power Grid Engineering Cost. Due to the large amount of complex power grid construction project and the long construction cycle, there are many risk factors that affect the project cost. In order to accurately identify the cost risk factors, based on the management theory of the entire process of power grid construction, this paper divides the risk sources into five categories according to the five stages of power grid construction: risks in investment decision-making stage, risks in design stage, risks in bidding stage, risks in construction stage, and risks in final account stage [12]. Then, the risk sources of each stage are broken down layer by layer, and finally the RBS tree is constructed, as illustrated in Figure 4.

5.3. Construction of WBS-RBS Risk Identification Matrix for Power Grid Engineering Cost. Since the key risk factors of cost will be identified and the evaluation index will be optimized later, the probability of risk events and the degree of possible loss to the project are not considered here. The risk factors that affect power grid engineering cost are listed, as shown in Table 1.

\section{Screening of Key Indicators of Cost Risk by Using the Membership Degree Method}

The cost risk factors for the entire process of power grid construction project listed in Table 1 are the preliminary identification index system. The number of indicators in this 
The entire process cost management of power grid engineering $W$

\begin{tabular}{cccccc}
\multicolumn{1}{l|}{} & & & \\
$\begin{array}{c}\text { Investment } \\
\text { decision-making }\end{array}$ & $\begin{array}{c}\text { Budget estimation } \\
\text { management in } \\
\text { stage } W_{1}\end{array}$ & Bidding & Budget in & Final account \\
design stage $W_{2}$ & stage, $W_{3}$ & construction & in completion \\
stage $W_{5}$
\end{tabular}

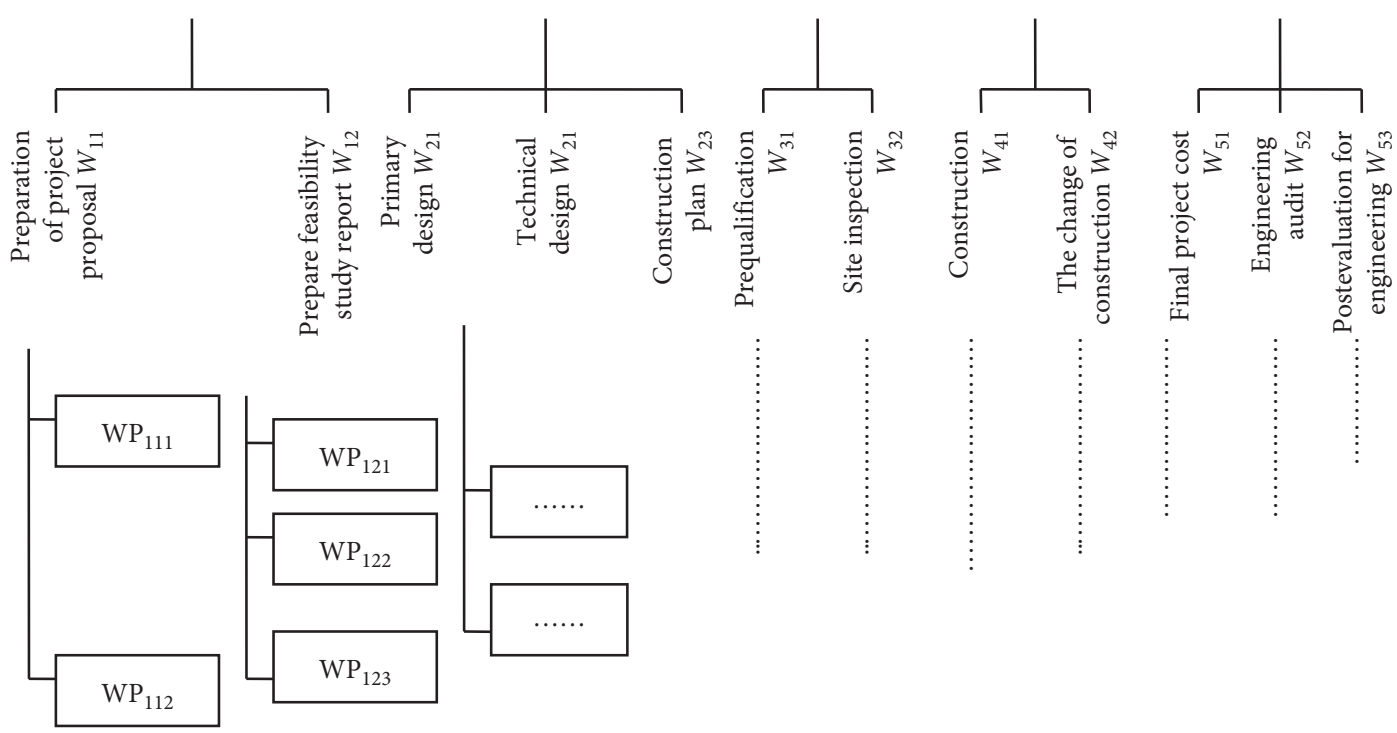

FIGURE 3: WBS diagram for power grid construction project.

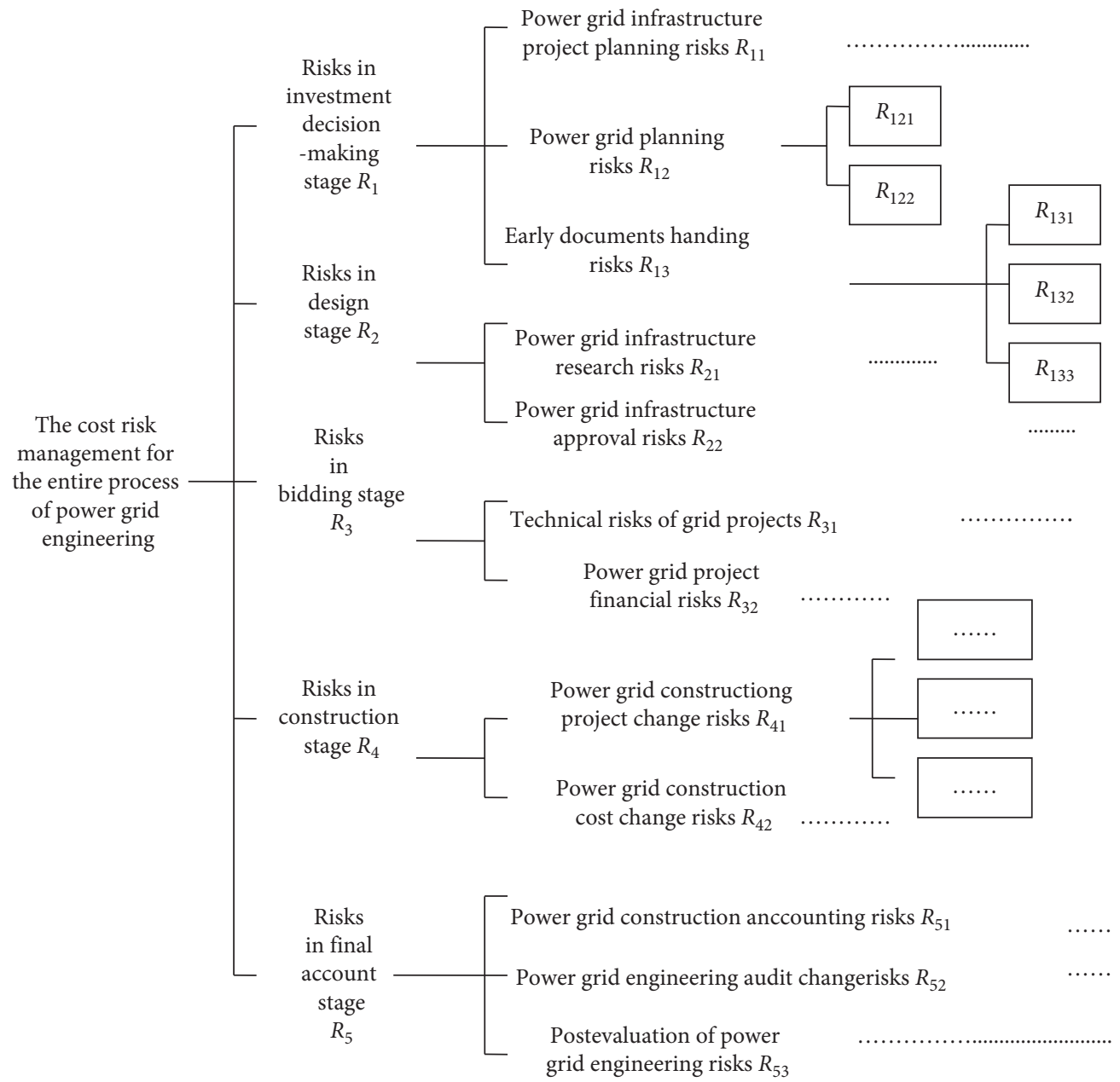

FIGURE 4: RBS diagram for power grid engineering project. 
TABle 1: Preliminary identification of risk factors in the entire process of power grid engineering cost.

\begin{tabular}{lc}
\hline $\begin{array}{l}\text { The first-level } \\
\text { indicator }\end{array}$ & The second-level indicator \\
\hline Risk of power grid planning $\left(R_{11}\right)$ \\
$\begin{array}{l}\text { Risk of investment } \\
\text { decision }\left(R_{1}\right)\end{array}$ & $\begin{array}{c}\text { Risk of planning of power grid capital } \\
\text { construction project }\left(R_{12}\right)\end{array}$
\end{tabular}

Risk of handling of preliminary documents $\left(R_{13}\right)$

Risk of project establishment and research in power grid capital construction $\left(R_{21}\right)$

Risk of project establishment and approval in power grid capital construction $\left(R_{22}\right)$

Risk of power grid engineering technology Risk of experience of tendering and bidding companies $\left(R_{311}\right)$, risk

\begin{tabular}{|c|c|}
\hline Risk of bidding $\left(R_{3}\right)$ & Risk of power grid engineering finance $\left(R_{32}\right)$ \\
\hline $\begin{array}{l}\text { Risk of construction } \\
\left(R_{4}\right)\end{array}$ & $\begin{array}{l}\text { Risk of project change in power grid capital } \\
\text { construction }\left(R_{41}\right) \\
\text { Risk of cost change in power grid capital } \\
\text { construction }\left(X_{42}\right)\end{array}$ \\
\hline & $\begin{array}{c}\text { Risk of final accounts in power grid } \\
\text { engineering }\left(R_{51}\right)\end{array}$ \\
\hline
\end{tabular}

Risk of final accounts $\left(R_{5}\right)$

Risk of audit in power grid engineering $\left(R_{52}\right)$

Risk of postevaluation for power grid engineering $\left(R_{53}\right)$

system is complex. In the actual project risk analysis, the relevant risk prevention and control personnel are required to collect massive data and information, so as to further analyze the complex data and draw conclusions. This is undoubtedly a time-consuming and labor-consuming huge project, which greatly reduces the evaluation efficiency of the final risk indicators. Moreover, there are subjective evaluation indicators in the preliminary identification index system, which may reduce the objectivity and accuracy of the evaluation results. Therefore, this paper takes the form of a questionnaire. Firstly, it collects the opinions of experts in the related fields of engineering cost extensively and adopts Likert scale method to ask the corresponding experts to score the preliminary indicators and further adjust the preliminary indicators according to the score results. Secondly, it combines the membership degree method to calculate the membership degree value of the risk index, selects the key indicators that affect the cost risk of power grid engineering based on the membership threshold, and establishes the risk evaluation index system so that it can be applied to the entire process of risk evaluation of power grid engineering cost in practice.

6.1. Distribution and Recovery of Questionnaires. The questionnaire design is based on Likert scale method, and it adjusts the measurement method appropriately. Specified
The third-level indicator

Risk of power load forecasting $\left(R_{111}\right)$, risk of economic situation evaluation $\left(R_{112}\right)$

Risk of scarcity of capital construction land resource $\left(R_{121}\right)$, risk of planning connection for power grid engineering cities $\left(R_{122}\right)$, risk of planning and coordination in cross-sectoral engineering $\left(R_{123}\right)$, risk of planning of supporting projects for power grid construction

$$
\left(R_{124}\right)
$$

Risk of law and policy $\left(R_{131}\right)$

Risk of purchase price of capital construction equipment $\left(R_{211}\right)$, risk of participation in power grid engineering audit $\left(R_{212}\right)$, risk of young crop compensation for power grid capital construction project $\left(R_{213}\right)$, risk of selection of design company $\left(R_{214}\right)$

Risk of project approval cycle $\left(R_{221}\right)$, risk of allocation of power grid engineering approval personnel $\left(R_{222}\right)$ of technical level of construction company $\left(R_{312}\right)$

Risk of inner ability to pay wages in advance of construction companies $\left(R_{321}\right)$, risk of target profit margin $\left(R_{322}\right)$

Risk of project change notice $\left(R_{411}\right)$, risk of tracking of capital construction project planning $\left(R_{412}\right)$

Risk of land acquisition fund $\left(R_{421}\right)$, risk of machinery, material and labor cost $\left(R_{422}\right)$

Risk of final accounts $\left(R_{511}\right)$, risk of engineering payment $\left(R_{512}\right)$

Risk of audit quality of final accounts $\left(R_{521}\right)$, risk of audit of final accounts $\left(R_{522}\right)$, risk of separate audit of "quantity and price" in final accounts $\left(R_{523}\right)$

Risk of completion rate of power grid engineering $\left(R_{531}\right)$, risk of evaluation after project completion $\left(R_{532}\right)$

score is as follows: 1-5 points, of which 1-not important, 2generally important, 3-relatively important, 4-important, and 5-very important. The lower the score of an indicator, the less important it is. It can be eliminated within a certain standard and range, and the remaining indicators can establish the risk evaluation index system. This paper adopts e-mail, on-site distribution, and other methods to distribute the questionnaire. The questionnaire will be distributed to experts in the industries such as construction companies, survey and design companies, and supervision companies, as well as relevant researchers in universities and research institutes.

A total of 120 questionnaires were distributed to relevant parties involved in the construction project, and 116 questionnaires were recovered as required. The validity of the questionnaire is divided according to the degree of convergence of the selection results. If the degree of convergence is too high, it is regarded as an invalid questionnaire, and the invalid questionnaire is eliminated. Based on this criterion, 7 questionnaires returned were invalid and 109 questionnaires were effectively recovered, with a recovery rate of $90.8 \%$. The statistical results of the entire process of the risk evaluation system of power grid engineering cost are shown in Table 2 . 
TABLE 2: Score statistics.

\begin{tabular}{|c|c|c|c|c|c|}
\hline \multirow{2}{*}{ Index sign } & \multicolumn{5}{|c|}{ Score distribution } \\
\hline & 5 & 4 & 3 & 2 & 1 \\
\hline$R_{111}$ & 9 & 25 & 37 & 48 & 0 \\
\hline$R_{112}$ & 6 & 35 & 30 & 38 & 0 \\
\hline$R_{121}$ & 10 & 40 & 33 & 20 & 6 \\
\hline$R_{122}$ & 0 & 1 & 28 & 59 & 21 \\
\hline$R_{123}$ & 24 & 37 & 33 & 15 & 0 \\
\hline$R_{124}$ & 15 & 36 & 21 & 37 & 0 \\
\hline$R_{131}$ & 0 & 3 & 34 & 56 & 16 \\
\hline$R_{211}$ & 0 & 18 & 39 & 42 & 10 \\
\hline$R_{212}$ & 2 & 30 & 35 & 31 & 11 \\
\hline$R_{213}$ & 0 & 14 & 56 & 26 & 13 \\
\hline$R_{214}$ & 10 & 35 & 45 & 10 & 9 \\
\hline$R_{221}$ & 0 & 0 & 37 & 58 & 14 \\
\hline$R_{222}$ & 1 & 13 & 24 & 32 & 39 \\
\hline$R_{311}$ & 0 & 38 & 37 & 24 & 10 \\
\hline$R_{312}$ & 14 & 46 & 32 & 17 & 0 \\
\hline$R_{321}$ & 11 & 29 & 41 & 17 & 11 \\
\hline$R_{322}$ & 0 & 19 & 30 & 35 & 25 \\
\hline$R_{411}$ & 2 & 22 & 60 & 25 & 0 \\
\hline$R_{412}$ & 11 & 23 & 36 & 31 & 8 \\
\hline$R_{421}$ & 9 & 23 & 37 & 49 & 0 \\
\hline$R_{422}$ & 0 & 14 & 35 & 36 & 24 \\
\hline$R_{511}$ & 0 & 14 & 36 & 40 & 19 \\
\hline$R_{512}$ & 0 & 24 & 47 & 38 & 0 \\
\hline$R_{521}$ & 0 & 0 & 25 & 53 & 31 \\
\hline$R_{522}$ & 0 & 21 & 47 & 37 & 4 \\
\hline$R_{523}$ & 33 & 40 & 23 & 13 & 0 \\
\hline$R_{531}$ & 21 & 53 & 32 & 3 & 0 \\
\hline$R_{532}$ & 0 & 15 & 59 & 33 & 2 \\
\hline
\end{tabular}

6.2. Reliability and Validity Tests of Questionnaire Results. In order to ensure the objectivity and accuracy of the questionnaire results, the corresponding data will be tested for reliability and validity. SPSS 17.0 mathematical statistical analysis software was adopted to perform Cronbach test on the data collected from a valid questionnaire. The results show (as shown in Table 3) that Cronbach's Alpha coefficient is 0.811 . When this value is greater than 0.8 , it indicates that the preliminary evaluation index has passed the reliability test and has a relatively ideal reliability. The validity test results show (as shown in Table 4) that the $\mathrm{KMO}$ sample measurement value is 0.712 , which is greater than 0.5. Bartlett sphericity test value is extremely small and much less than 0.001 , which indicates that the preliminary risk index is suitable for factor analysis, so it passes the validity test.

\subsection{Selection of Key Risk Indicators and Establishment of the} Indicator System by Using the Membership Degree Method. In view of the process of social science research, membership degree is a concept adopted to analyze the evaluation ability of a specific indicator on the target to be evaluated. As the number of preliminary risk indicators constructed by WBSRBS matrix is relatively complex, which affects the application effect of risk evaluation index system in actual projects, the membership degree method is adopted to
TABLE 3: Reliability analysis results of the questionnaire.

\begin{tabular}{lcc}
\hline $\begin{array}{l}\text { Cronbach's } \\
\text { alpha }\end{array}$ & $\begin{array}{c}\text { Standardized item-based } \\
\text { Cronbach's alpha }\end{array}$ & $\begin{array}{c}\text { The number of } \\
\text { terms }\end{array}$ \\
\hline 0.811 & 0.920 & 28 \\
\hline
\end{tabular}

TABLE 4: Validity analysis results of the questionnaire.

\begin{tabular}{lc}
\hline Adequate sampling Kaiser-Meyer-Olkin measurement & 0.712 \\
\hline Bartlett spherical degree of inspection & \\
The approximate chi-square & 1619.023 \\
Df & 286 \\
Sig. & 0.000 \\
\hline
\end{tabular}

TABle 5: Cost risk indicator score.

\begin{tabular}{lcc}
\hline $\begin{array}{l}\text { Index } \\
\text { code }\end{array}$ & $\begin{array}{c}\text { The number of } \\
\text { specialists }\end{array}$ & $\begin{array}{c}\text { The membership degree } \\
\left(Z_{\mathrm{t}}\right)\end{array}$ \\
\hline$R_{111}$ & 71 & 0.651376 \\
$R_{112}$ & 71 & 0.651376 \\
$R_{121}$ & 83 & 0.761468 \\
$R_{122}$ & 29 & 0.266055 \\
$R_{123}$ & 94 & 0.862385 \\
$R_{124}$ & 72 & 0.660550 \\
$R_{131}$ & 37 & 0.339450 \\
$R_{211}$ & 57 & 0.523936 \\
$R_{212}$ & 67 & 0.614679 \\
$R_{213}$ & 63 & 0.642202 \\
$R_{214}$ & 90 & 0.825688 \\
$R_{221}$ & 37 & 0.339450 \\
$R_{222}$ & 38 & 0.348624 \\
$R_{311}$ & 75 & 0.688073 \\
$R_{312}$ & 92 & 0.844037 \\
$R_{321}$ & 81 & 0.743119 \\
$R_{322}$ & 49 & 0.449541 \\
$R_{411}$ & 64 & 0.770642 \\
$R_{412}$ & 70 & 0.642202 \\
$R_{421}$ & 69 & 0.633028 \\
$R_{422}$ & 49 & 0.449541 \\
$R_{511}$ & 56 & 0.458716 \\
$R_{512}$ & 66 & 0.651376 \\
$R_{521}$ & 25 & 0.229358 \\
$R_{522}$ & 18 & 0.623853 \\
$R_{523}$ & $R_{531}$ & 0.880734 \\
$R_{532}$ & 50.972477 \\
& & 0.678899 \\
\hline
\end{tabular}

optimize the preliminary index system and screen the key indicators that affect the risk of power grid engineering cost, so as to establish a flexible, simple, and efficient risk evaluation index system suitable for the actual operation in China [8].

Let $\{R\}$ represent a fuzzy set, which represents the risk index system of power grid engineering cost. Each element in $\{R\}$ (the risk index) is represented by $R_{\mathrm{t}}$; then the analysis of membership degree can be performed on $R_{\mathrm{t}}$. And ask the $n$ experts selected in the previous questionnaire to score the ability to evaluate many indicators of the preliminary cost risks of power grid engineering. The score result obtained for a certain $R_{\mathrm{t}}$ indicator is represented by the membership degree value $Z_{\mathrm{t}}$. $Z_{\mathrm{t}}$ is 


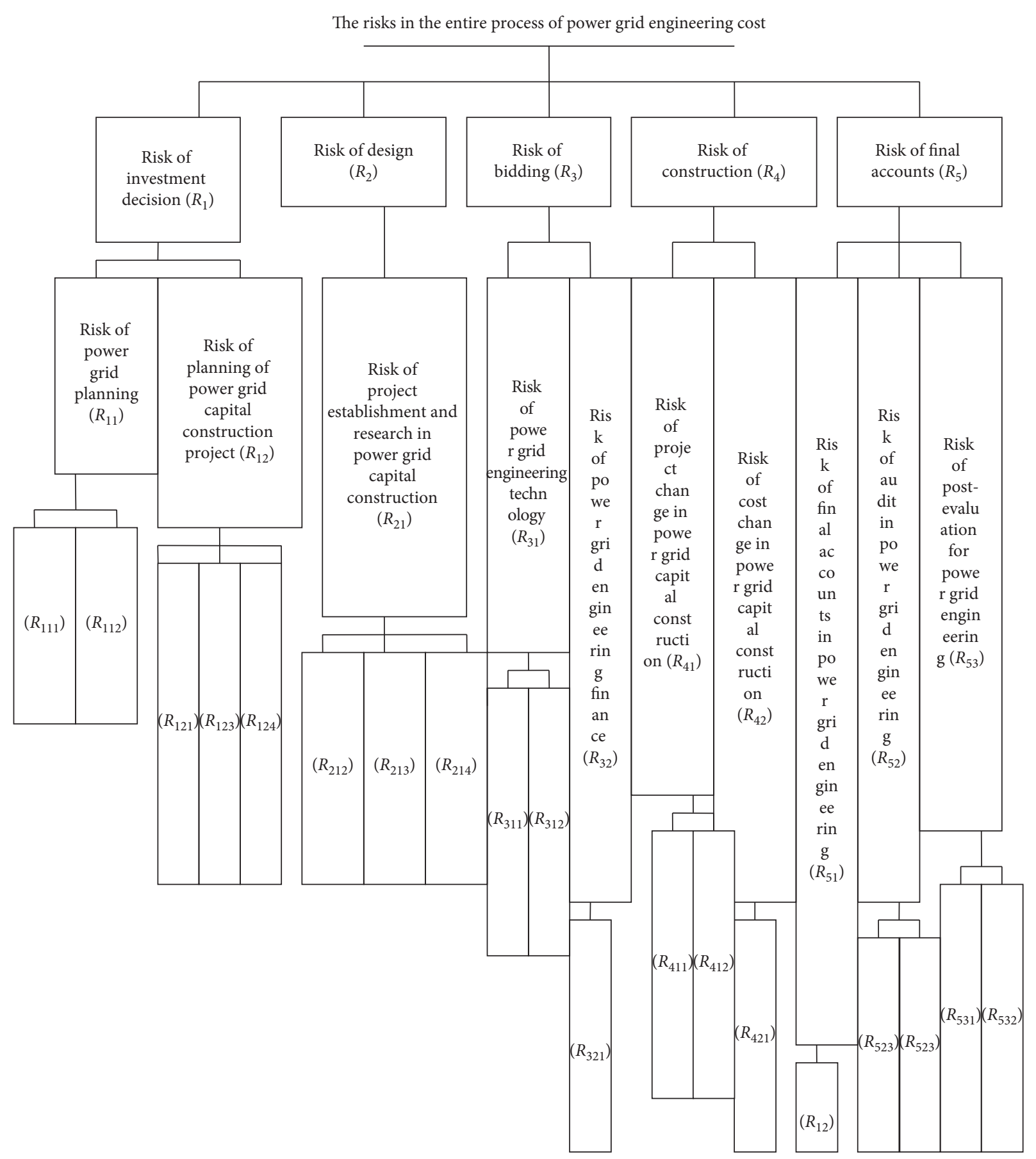

FIGURE 5: Risk evaluation index system of power grid engineering cost.

calculated by the formula $Z_{\mathrm{t}}=m_{\mathrm{p}} / n$, where $m_{\mathrm{p}}$ represents the number of experts who choose very important, important, and relatively important and $n$ represents the total number of experts who participate in scoring. The larger the value of $Z_{t}$, the greater the possibility that the indicator $R_{\mathrm{t}}$ belongs to the fuzzy set $\{R\}$. That is, it can be judged that this indicator is critical in the evaluation system and can be retained as a formal evaluation indicator; otherwise, it is necessary to eliminate it to achieve the purpose of optimizing the evaluation indicator system. This paper analyzes the 109 valid questionnaires collected and calculates the membership degree of the risk evaluation index system for the entire process of power grid engineering through the formula $Z_{\mathrm{t}}=m_{\mathrm{p}} / n$, as shown in Table 5 .

At present, there is no authoritative conclusion on the determination of the threshold value in the analysis of membership degree. Therefore, this paper calculates the sum of the membership values of all the preliminary cost risk indicators shown in Table 3 and then takes the average value as the threshold value of the selected risk evaluation index system. That is, if the membership degree value $Z_{\mathrm{t}}$ of the risk indicator $R_{\mathrm{t}}$ is less than the average membership degree 0.614387, the 
evaluation system is excluded. The risk indicators that have not been excluded in the end are the key indicators for the risk evaluation of power grid engineering cost, and the key indicators are adopted to establish the risk evaluation index system of power grid engineering cost, as illustrated in Figure 5 (note: due to space limitations, the third-level indicators are only represented by letters as seen in Table 1).

\section{Conclusion}

Due to the influence of various internal and external uncertainties, there are great risks which often lead to the overrun of project budget in the power grid projects. This paper combines the characteristics of power grid engineering and based on the characteristics of project cost management at each stage of power grid construction, the connotation of cost risk management, and the effect of risk evaluation, this paper analyzes from the perspective of cost risk management of the entire process of power grid engineering and adopts the WBS-RBS method for the first time to identify risks in the entire process of power grid engineering by referring to the application of WBS-RBS method in the cost management of hydraulic project engineering. This is more comprehensive than traditional methods such as decision tree to identify power grid cost risk factors. At the same time, this paper studies the efficient application of the membership degree method in government performance evaluation and highway engineering management performance evaluation and identifies and adopts the membership degree method to identify and screen the complicated preliminary indicators of power grid cost risk, so as to acquire key indicators that affect project cost risk.

The establishment of WBS-RBS membership analysis method not only enables the power grid construction company to prevent risks well in the construction process, but also enables the supervisor to conduct a key investigation on the behaviors of all parties involved in the project construction process.

Finally, the WBS-RBS membership analysis method was applied to study the risk of power grid engineering cost in China. A simple scientific risk evaluation index system suitable for the power grid engineering cost in China is constructed in order to provide beneficial research ideas for China's risk evaluation and management of power grid engineering cost.

\section{Data Availability}

The data in this article can be shared with relevant institutions or individuals for research.

\section{Conflicts of Interest}

The authors declare that there are no conflicts of interest.

\section{Acknowledgments}

This work was supported by the doctoral research fund of North-East China Electric Power University that started the project BSJXM-2019106.

\section{References}

[1] W. Zhang and Y. Duan, "Social stability risk relationship model of major engineering projects based on fuzzy-ISM," Journal of Civil Engineering and Management, vol. 36, no. 5, pp. 102-108, 2019.

[2] X. Wu, L. Lin, and J. Gu, "Analysis on comprehensive benefit of life-cycle engineering consulting project in power transmission and transformation engineering: taking seven pilot projects of state grid as examples," Construction Economy, vol. 41, no. 1, pp. 15-21, 2020.

[3] X. Ding and F. Xu, "Bayesian network modeling for project risk management: a case study of Hong Kong-zhuhai-Macao bridge," Journal of Systems and Management, vol. 27, no. 1, pp. 176-192, 2018.

[4] K. Nan, S. Gui, J. Wang et al., "Cost of the distributed power distribution network risk assessment simulation research," Computer Simulation, vol. 34, no. 3, pp. 96-100, 2017.

[5] Z. Zhao and Q. Man, "Evolutionary game analysis of risk management behavior of major infrastructure projects based on prospect theory," Journal of Systems and Management, vol. 27 , no. 1, pp. 99-117, 2018.

[6] X. Huang, "Study on monte-carlo method based risk assessment model of power transmission project cost," Modern Electronics Technique, vol. 40, no. 20, pp. 178-180, 2017.

[7] L. Z. Kong, "Risk evaluation of engineering project cost based on set pair analysis," Journal of Civil Engineering and Management, vol. 33, no. 1, pp. 90-96, 2016.

[8] Y. Xue, "Risk identification of water conservancy projects in the whole process of WBS-RBS method," Water Conservancy and Hydropower in Rural China, vol. 23, no. 2, pp. 71-78, 2018.

[9] J. Chen, "Risk Identification of WBS-RBS method in subway construction," The North Project, vol. 11, no. 1, pp. 109-111, 2017.

[10] N. RenB. Han et al., "Project risk identification and assessment based on WBS-RBS-DSM," Systems Engineering, vol. 32, no. 11, pp. 97-100, 2014.

[11] X. Fang W. Zhang et al., "Optimization of evaluation index cost risk based system from power transmission project on rough seta theory," Journal of Civil Engineering and Management, vol. 32, no. 4, pp. 40-47, 2015.

[12] J. Wang and Y. C. Li, "Prediction model for construction cost based on grey relational analysis PSO-SVR," Journal of Huaqiao University (Natural Science Edition), vol. 37, no. 6, pp. 708-713, 2016.

[13] X. Cui Y. Zhang et al., "Power transmission project cost risk assessment based on matter element and extension theory," Journal of Civil Engineering and Management, vol. 12, no. 4, pp. 90-94, 2015.

[14] J. Wang and L. Ding, "Analysising the main impact factors on the build price of the $500 \mathrm{kV}$ power line engineering," Journal of Northeast Dianli University (Natural Science Edition), vol. 32, no. 5, pp. 9-11, 2012. 